\title{
A PRESENÇA DO SAGRADO EM VIVA O POVO BRASILEIRO*
}

\author{
Marilene Welnhardt \\ Universidade Federal do Paraná \\ RESUMO
}

VIVA O POVO BRASILEIRO apresenta-se como o texto ideal para uma leitura de orientação sociológica, na medida que evidencia uma visão deliberadamente critica da formação da pátria brasileira. Igualmente sedutor mostra-se o estudo de carater estrutural e formal, seja pela extensäo do tempo ficcional seja pela instauraçāo da ironla provocada pela posiçāo do narrador e pela linguagem.

No sentido de somar e artícular com essas e/ou outras propostas de leitura, parece-nos possível aplicar ao romance os princípios da teoria do historiador das religiōes Mircea Eliade. O texto focaliza o choque entre uma socledade primitiva e uma sociedade em vias de modernização. Nossa atenção centrar-se-á nas manifestaçōes do sagrado próprias da sociedade arcaica e na sobrevivência de procedimentos primitivos no homem civilizado. Elementos para essa análise existem em profusão: festas rituais, espaços sagrados, tempos fortes, plantas com poderes mágicos, rituais de iniclaçāo, Irmandade secreta, transformaçāo de tempo histórico em tempo mitico, feiticeiras, reencarnaçāo, objetos sacralizados...

Evidentemente, não se trata de confirmar as pesquisas de Elíade com os dados de uma obra de ficção, nem de pretender uma relação consciente da parte de Joāo Ubaldo com tais pesquisas, mas de vislumbrar alguns dos caminhos encontrados para, trabalhando com um universo ficcional que reúne concepçōes européias importadas, tradiçőes africanas transplantadas e costumes autóctones desfigurados, atingir o efeito estético.

- Este texto fol apresentado no II ENCONTRO NACIONAL DA ANPOLL. sob a forma de Comunlcacto. 
Os comentários e resenhas aparecidos quando da publicação do romance de João Ubaldo Ribeiro apontam quase unanimemente para a leitura de caráter sociológico, rumo inevitável para uma obra que o próprio autor define, em entrevista dada a Leia, como "não a história - mas uma história - de um possivel surgimento de consciência de nacionalidade - consciência de naçāo e um pouco também de consciência de classe, ou, pelo menos, de consciência social no Brasil." O contato com o texto de imediato desperta também o interesse para os recursos de estruturaçāo usados para cobrir mais de três séculos de tempo ficcional, bem como para a habilidade da voz narrativa que, na sua pluralidade, instaura o humor pela ironia, evitando o panfletarismo fácil.

Entretanto, vendo a obra de arte como uma somatória de aspectos que só adquirem significação quando vistas no todo, procuramos perceber outros niveis que corroboram para o efeito encantatório final que permite a experiência estética.

Uma característica que logo se mostra é a questão da religiosidade presente na obra: o catolicismo dos brancos, ou seja, da classe detentora do poder, e as crenças dos negros, do povo, isto é, dos explorados. Pensando a religião não como um fator individual ou um adorno da sociedade, mas como um dos componentes estruturadores de um espaço histórico e social, percebemos a possibilidade de conduzir a leitura deste aspecto do romance nāo como uma mera discussão sobre religiōes, para reafirmar o decantado sincretismo religioso, mas para ferir assim a problematizaçāo do texto, que é o confronto entre o arcaico e o civilizado, o momento da ruptura entre o tempo mítico e o histórico. Buscamos então subsidios nas investigações do historiador das religiōes Mircea Eliade, detendo-nos em seus estudos mais genéricos e desprezando os ensaios que particularizam uma única religião. Frizamos que o nosso objetivo nāo é estudar as convicçōes do autor, a religiāo católica e/ou o candomblé no Brasil, mas de detectar como, conscientemente ou nāo, o autor trabalha, entre outros, com elementos próprios do sagrado para recriar esteticamente a complexa realidade bra. sileira.

A pesquisa de Eliade é no sentido de, pela comparaçāo entre diversas manifestaçōes, detectar, em todas as sociedades, a presença do sagrado com características que, em geral, se aproximam, seja quanto ao aspecto externo, seja

1 Berra. Cristina. A formacho da nacionalidade brasileira como fol vista por Jolo Ubaido Ribeito. na mansidío da liba de Itsparica. Leia. Săo Paulo. 7(75):10. Jan. 1985. 
quanto ao móvel que as determina, verificando-se analogias entre fenômenos culturais diferentes, o que fornece dados à discussāo sobre arquétipo, aflorada mas não aprofundada pelo estudioso.

Na entrevista já citada, a propósito de uma pergunta sobre o fio narrativo, o autor responde que:

o fio da história é um artifício que talvez até nem seja muito postiço, pensando bem. Eu usei como fio narrativo a existência de uma "alminha". Mas o livro não é kardecista, não. Eu não sei nada de espiritismo, mas há uma série de teses e informações pseudo-espíritas que são tiradas da minha cabeça."

Essa "alminha" está presente em todo o tempo ficcional, ora encarnada, podendo animar não só seres humanos mas também bichos e plantas, ora na sau condição espiritual, assistindo, do "poleiro das almas", os eventos terrenos, ora adejando pelos lugares onde encarnara, ora se manifestando nos rituais. O discurso registra reiteradamente o medo e as inconveniências da volta ao plano físico em luta com o desejo irresistível de aprender e evoluir, o que só se consegue pela encarnação. Particularmente em Mito e Realidade, Eliade focaliza a crença da volta ao mundo, geralmente uma for. ma de sofrimento e regeneração, em diversas culturas arcaicas. Escolhemos, como ilustração, o pensamento indiano, bastante distante de nossas tradições: "o sofrimento baseia-se e é indefinidamente prolongado no mundo pelo karma, pela temporalidade: é a lei do karma que impõe as inumeráveis transmigraçōes, esse eterno retorno à existência e, portanto, ao sofrimento. Libertar-se da lei kármica equivale à 'cura'." O pesquisador constata "uma certa continuidade de comportamento humano no que concerne ao Tempo", concluindo que "para curar-se da obra do Tempo, é preciso 'voltar atrás' e chegar ao 'princípio do Mundo'."';

O texto realiza, em diversos momentos, a volta ao prin. cípio, senão do mundo, pelo menos da cultura brasileira, tanto por meios naturais como mágicos. Maria da Fé, a personagem central nesta imensa galeria, pesquisa sua genealogia; uma feiticeira ensina ao branco Patrício Macário a teoria da reencarnação e do parentesco espiritual para explicar o interesse que uma desconhecida em transe manifesta por ele. Na mesma oportunidade, na reconstituição da familia 
de almas, a feiticeira constata que, do ponto de vista espiritual, Maria da Fé é ancestral de si mesma, realizando-se aí o retorno ao principio. Pode ser a explicação para o seu papel de redentora dos oprimidos, uma das linhas fundamentais do romance. A propósito do relato que recupera o passado, não se pode desprezar a narrativa de um cego do sertão, qualificado como narrador famoso, não fosse suficiente a tradição que habilita o cego como contador por excelência. Sua narração, só iniciada à noite para nāo criar rabo, na melhor tradição, remonta à cosmogonia, para chegar à história do Brasil e. particularmente, à ação, ou melhor, a lenda de Maria da Fé, transformada em heroina com poderes sobrenaturais. Vale ainda considerar que o próprio fato de escrever - e ler - o romance é uma forma de "cura".

$\mathrm{Na}$ mesma linha de raciocínio explica-se a noçāo de tempo para o homem arcaico, para quem não existem três tem. poralidades, mas uma concepção cíclica permitindo que tudo se renove periodicamente e se presentifique em cerimoniais de purificação que abolem a história e atualizam a cosmogonia. Parece paradoxal que se evoque a idéia primitiva de anulação da passagem do tempo a propósito de um romance que data todos os eventos, marca do homem histórico. En. tretanto, contrapondo-se a essa característica exterior, per. manece o substrato arcaico. $€$ o caso das cerimônias ritualísticas na Capoeira do Tuntum, que permanecem inalteradas na essência e mereceräo exame mais acurado. $O$ mesmo princípio rege a Festa de Sāo Gonçalo que, apesar do nome cristão, comporta elementos pagãos. O santo é venerado não por suas virtudes cristãs mas por seu poder no plano da sexualidade, imperando a licenciosidade tanto no plano da linguagem, pelos hinos que the são dirigidos, como no dos atos, quando a orgia deixa de ser pecaminosa, associada aos exageros na bebida e na comida. M. Eliade explica a ocorrência de cerimoniais orgiásticos como a recuperação do caos, da desordem primordial, império do instintivo e do animalesco, até que a partir de uma hierofania se instaure o cosmos, segundo o modelo divino. Para sublinhar a transgressão aos padrões civilizados, no caso, católicos, o narrador assume uma postura moralizante, escandalizado com o que acon. tece longe dos olhos fiscalizadores da Corte.

Note-se que os fatos destacados para ilustrar a concepção de tempo cíclico ocorrem nas camadas populares, preferencialmente entre os negros, os mais próximos de uma sociedade primitiva. Mas o traço pode ser percebido também, de forma mais esmaecida e com algumas diferenças essenciais, no mundo dos brancos. $\mathrm{E}$ o caso de Festa de Santo 
Antônio promovida anualmente por Antônia Vitória, a $\mathrm{Ba}$ ronesa de Pirapuama. A devoção é cumprida em data definida, com novenas, missa, divertimentos e comilança para o povo. Mas em nenhum dos níveis sente-se a presença do santo. E uma comemoração, não uma atualização. As fronteiras entre as classes sociais permanecem claramente delimitadas, sem a comunhão característica do arcaico. Os escravos realizam as representações que lhes são determinadas, amestradamente, para conviver com o sagrado à sua maneira, no tempo e espaço apropriados, isto é, sacrais - à noite, na Capoeira do Tuntum.

Outra festa registrada é a de Sāo João. A marca cristã fica por conta do nome do santo, mas o objetivo é profano: o avô quer alegrar a neta adotiva que viu o assassinato da mãe. $O$ tom é de irreverência, detectando-se reminiscências pagãs tratadas de forma jocosa: Nego Leléu fantasia-se de São João, presentificando-o; os jogos de adivinhação lembram os processos arcaicos de previsão do futuro; as foguejras remetem aos poderes mágicos do fogo; o cuidado em apresentar uma grande variedade de comidas tipicas recorda o ato de alimentar-se como ritual; finalmente, a licenciosidade, ainda que no caso ocorra apenas no plano da lingua. gem, remete à indistinção arcaica entre o sagrado e a sexualidade.

Focalizemos as cerimónias ritualísticas da Capoeira do Tuntum, não enquanto peças do folclore afro-brasileiro, mas como manifestações da religiosidade arcaica. Por duas vezes o narrador descreve detalhadamente as funçōes realizadas no local denominado Capoeira do Tuntum. Ambas acontecem correspondendo, no calendário católico, à Festa de Santo Antônio: 14 de junho de 1827 e 13 de junho de 1871. Apesar. de transcorridos mais de quarenta anos entre um evento e outro, não se verificam alterações na essência e há indicações de que ocorrem periódica e freqüentemente. A escolha das datas é determinada pelo enredo, momentos cruciais para as personagens centrais, embora elas não dfesempenhem papéis de importância nos ritos. A primeira função acontece na sequiência da festa de devoção da baronesa, depois da ordem para todos irem dormir. Já durante a festa os negros foram disfarçadamente se reunindo numa quina do terreiro, realizando uma espécie de dança preparatória. Na capoeira tudo se transforma. Lá os negros já não são escravos, mas senhores de um saber que escapa ao poder dos brancos. A transcrição é mais eloqtiente do que qualquer paráfrase:

Sim, não eram os mesmos, esses negros antes foliando no terreiro da capela e agora espalhados em 
pequenos grupos aqui e ali na capoeira. Eram mandingueiros, isso sim, feiticeiros da noite, gente mandraca que só ela, gente versada nas coisas da pedra cristalina, do poder das almas e das divin. dades trazidas da Africa."

Só neste trecho pululam caracteristicas apontadas por Eliade como comuns a várias sociedades arcaicas. Dizer homem arcaico equivale a religioso, uma vez que a religiāo não se separava dos demais aspectos da vida. Sem senhores, os negros manifestam suas tradições autênticas. Todos são crentes, iniciados ("gente mandraca"), saber que nāo pode ser entendido pelos padrões do pensamento histórico, que privilegia o empirico-racional em detrimento do sensorial. Estão presentes os sacerdotes ("feiticeiros", "mandingueiros"), que realizam a intermediação entre o físico e o mágico. Eliade dedica todo um capítulo do Tratado da His: tória das Religiōes às diversas formas de crenças em pedras mágicas, acentuando que elas jamais são adoradas enquanto tais, mas porque representam e imitam alguma outra coisa (no caso, "as coisas da pedra cristalina"). No mesmo estudo Eliade aborda, em diversas ocasiōes, a concepção de morte como passagem para outro Universo que tem pontos de intersecção com o dos vivos, sendo possivel o retorno à convivência humana em espaços e tempo definidos ("o poder das almas"). Finalmente quanto às divindades, o politeismo é uma constante no mundo arcaico.

O tempo cronológico é abolido, não só pela presença dos antepassados, o próprio narrador declarando: "durante esse tempo impossivel de medir". A dança e a música produzida por instrumentos que têm sua função sagrada assegurada por designaçōes especiais, fugindo do cotidiano também pe. la palavra, fazem parte integrante da transfiguração da realidade:

A orquestra dos negros também era outra agorá. Não eram mais tamborins, eram os ilus ( . . .); luão eram mais os ganzás, eram os amelês (...), etc. Do lado escuro da poeira, uma voz de mulher ecoou o refrão, logo outras acompanharam, logo a orquestra deu a primeira batida, logo os arbus. tos mudaram de cor e substância e as mulheres emergiram deles para dançar no clarāo das lumeeiras. (p. 150).

4 RIBEtro, Joåo Ubaldo. Viva o povo brasileiro. Rlo de Japelto. Nova Frontelra. 1984. p. 148 (Todas as demals citacóes desta obza encont:am-se no prćprio corpo do texto. com indicaçáo da página entre paréntescs). 
O outro cerimonial descrito pouco difere deste estruturalmente, tendo sua razāo de ser no desenrolar da trama. Acrescentam-se detalhes sobre a presença de comidas, de bebidas e do fumo. São pratos com ingredientes específicos, não considerados na sua função de alimentar apenas o corpo. Além de cachaça, há diversos licores cuja fabricação também pressupõe um saber reservado. Quanto ao fumo, não é "fumo tabaco, ( . . ) é fumo d'Angola" usado "para sentir coisas". $\mathbf{E}$ evidente que o autor deixa aí uma porta aberta para a explicação dos fenômenos como naturais, produzidos pela conjugação desses elementos. Mas o narrador não entra nesse mérito, confirmando o sacral pelos vaticínios e pelo relato de coisas passadas, se bem que estas também possam ser atribuidas à tradição oral.

Finalmente quanto ao espaço, a capoeira é descrita como um "território arredondado", de difícil acesso, com muitos caminhos que provocam desorientação. Até "o ar ali era diferente", ali onde "tudo é possivel". O espaço sagrado não é regido pelas mesmas leis do espaço profano, só permitindo o acesso dos iniciados. Aos outros ele impõe temor, caso do guarda-livros Amleto e do feitor Almério, sempre opressores, que nesta hora não ousam enfrentar o "desconhecido". Tema longamente trabalhado por Eliade é o simbolismo do "Centro", identificado pela hierofania. O primitivo só constrói sua morada, funda uma cidade ou erige um templo no local que se revelou como "Axis Mundi", variando de um povo para outro a forma de reconhecê-lo. A Capoeira do Tun. tum é o local da epifania por excelência, embora o argumento de que era necessário camuflar as práticas fetichistas possa relativizar a teoria. Mas ela não é invalidada, na medida que o narrador afirma que o ritmo era ouvido em toda a Armação do Bom Jesus, sem que ninguém ousasse se aproximar. Em favor do simbolismo do Centro, lembremos ainda que só um espaço virgem de traços civilizadus permitiria a manifestação do arcaico em seu estado puro.

A minuciosa análise do episódio visa frisar que, quando o arcaico está em seu meio, a harmonia é perfeita. A crise origina-se do choque com o histórico.

Em relação ao espaço geográfico onde se situam as ações, é possível ainda dar outro rumo à reflexão, talvez até mais significativo para nossa leitura, uma vez que não se trata de uma relação direta e transparente. Os acontecimentos situam-se predominantemente na Ilha de Itaparica. Num segundo momento aparecerá Salvador da Bahia. Já no final do século XIX, num enredo que remonta a meados do século XVII, transfere-se para o Rio de Jaeniro, passando pe- 
los campos sulinos e pelo sertāo nordestino, chegando a Sāo Paulo em 1972. Imediatamente percebe-se o fator ecoroómico como condutor dessa linha. Mas a narração não segue linearmente, não só porque se serve do flash-back, mas pelas idas e vindas das personagens. O próprio texto é construido en espiral. A Ilha de Itaparica pode ser vista como um espaço sagrado, pelo seu caráter geográfico que tanto remete ao mito cosmogônico (as terras separando-se das äguas), como ao princípio de que o local elevado permite a aproximação com o divino. E na ilha ainda que se situa Amoreiras, esse "espaço forte" por excelência, onde permanece urm sem número de almas desencarnadas. O narrador, disfarçado no pronome se marcando a indeterminação, reúne todas as explicaçōes dadas pelo povo, explicações que vão de pseudocientíficas a esotéricas, e compromete a todos que por ali habitaram ou habitam, dos índios tupinambás passando pelos "portugueses, espanhóis, holandeses e até franceses", alcançando "os pretos de várias naçōes da Africa (...) que foram os que melhor aprenderam a conviver com essa circunstância". (p. 15-6) A título de curiosidade, vale informar que João Ubaldo diz ter descoberto depois que Amoreiras é mesmo um "lugar misterioso", onde se conserva "o culto dos eguns, o culto dos mortos, único no Brasil".

Os representantes do arcaico poucas incursōes fazem fora do universo da ilha, enquanto os representantes do profano vão se afastando e ampliando seus horizontes, conse. quientemente minimizando o confronto entre os dois tipos de sociedade. Mas a própria ilha é progressivamente dessacralizada, processo marcado na linguagem. O toponimico, colocado junto com a data, na forma de cabeçalho de carta ou diário, vai se modificando. De "Ilha de Itaparica" ou, mais comumente, da designaçāo de diversos lugares da ilha, mar. ca de proximidade e intimidade, passa a "Denodada Ilha de Itaparica", na época da organização dos Voluntários da Pátria, para adentrar o século XX como "Estância Hidromineral de Itaparica".

Entretanto, uma das mais inquestionáveis manifestações do divino se dá num local muito diferente, identificando-se à teoria do mítico pelo distanciamento espacial. Trata-se da presença dos orixás nos campos do Tuiuti, para ajudar seus filhos baianos. Ainda que fora dos nossos propósitos, é inevitável lembrar o paralelo com os dois planos narrativos de Os Lusiadas. As entidades reúnem os traços das divindades pré-cristãs: seus poderes são limitados, têm características físicas e relações familiares, experimentam sentimentos de

5 BERRA, D. 10. 
compaixāo, de egoísmo, de tristeza e de despeito. Depois çue a batalha no plano terrestre já vai bem adiantada, Oxćssi pede a ajuda do pai Xangô e busca a colaboração dos orixás irmãos, cada $1 \mathrm{~m}$ perito em uma especialidade, para proteger seus filhos terrenos, de forma a preservar aqueles que respeitam os preceitos, cumprem as obrigações, fazem ofcrendas e sacrificios. A expedição de Oxóssi é demorada, com saudações ritualísticas e até recusas despeitadas que exigem o concurso de custosos artifícios. Mas como o tempo não corre paralelo nos dois Universos, o acordo ainda se faz a tempo de ajudar os brasileiros a reverterem o resultado da batalha. Os olixás falam diretamente ao espirito dos soldados seus filhos infundindo-lhes coragem e recorrem a expedientes como tombos acidentais que evitam tiros certeiros. O recurso narrativo empregado para não trair a verdade histórica dando uma vitória imediata aos brasileiros e o fim da guerra, é a perseguição de Omolu, "orixá da peste e da doença, senhor da lepra e da creca" (p. 452), e a reação dos entidades paraguaias, "estranhos seres de inacreditável aparência, (que) estavam prestes a sair de águas, árvores e nuvens, para também socorrer seus filhos" (p. 454). Fim todo este episódio o narrador é onisciente não deixando ao leitor a possibilidade de optar por uma explicação natural.

A religiāo do civilizado, o catolicismo, embora constante em toda a obra, não mostra qualquer função efetivamente espiritual. Os ofícios são meros atos sociais, que perderam todo o caráter sacral. O clero está sempre presente, mas a irreverência que merece do narrador atinge o caricatural. No começo da história sua presença é um fator de desequilibrio. a catequese dos jesuítas, em meados do século XVII, que confunde as idéias do caboco Capiroba, transformando-o em comedor de gente. Note-se que não se trata de antropofagia no sentido ritualistico, prática de alguns povos, mas resultado do choque de culturas. $O$ atrito da civilização européia com a cultura autóctone restringe-se a esse episódio, permanecendo no povo o substrato indígena já de forma muito diluída. Os demais padres estão perfeitamente enquadrados no regime, ratificando a opressão. $O$ cônego que visita a Armaçăo no início do século passado é a caricatura do europeu pseudo-ilustrado do século XVIII, querendo conciliar o conhecimento científico e a espiritualidade. Ele só entende a presença de pessoas cultas no Novo Mundo, suportando natureza tão hostil, com ares tão insalubres, e convivendo com seres bestializados, como manifestação da virtude cristā da caridade, na tentativa de trazer verdade e progresso em benefício dos brutos. $O$ diretor espiritual da baronesa 
transforma em inspiração divina tudo o que convém a ela, garantindo vida farta para ele. Entretanto, neste estágio, embora o discurso do narrador os desmascare, os sacerdotes ainda são respeitados.

Alguns anos depois, em Salvador da Bahia, o guardalivros mulato Amleto Ferreira se transformou no Comendador Amleto Henrique Nobre Ferreira-Dutton, nome conseguido graças à venalidade de um pároco, e banqueiro graças à fortuna hábil e trapaceiramente herdada do barão. Um filho rebelde, Patricio Macário, ocasiona a convocação de um conselho para comunicar a decisão do pai sobre o corretivo e punitivo a ser aplicado ao filho desnaturado: a carreira militar. O Monsenhor que o batizou também é chamado para decidir o destino do rapaz, mas não só nāo expressa qualquer opinião, como até ratifica e louva a decisão paterna, em atitude desmascaradamente bajulatória. Já o evento do batizado fora visto como acontecimento exclusivamente mundano, servindo para mostrar os progressos económicos e sociais do antigo auxiliar do barão. Outro filho, Clemente André, segue a carreira eclesiástica, dedicando-se a obras pias, configuradas na construção e manutenção de asilos para meninos desprotegidos. Mas, intercalando esses interesses piedosos e o cuidado com o caimento das batidas de seda estrangeira, patenteia-se o desvirtuamento e a perversão de sua caridade.

A fé da baronesa é patente, mas marcada pela idolatria que se aproxima do paganismo, como ilustra o episódio da quebra acidental de uma imagem, o que provoca reaçōes da dona como se os próprios santos tivessem sido ameaçados. Sua religiosidade baseia-se em promessas, podendo barganhar com o santo protetor de modo a atender também os interesses da protegida. Seu temor de um Ser Superior vingativo identifica seu deus mais a Jeová do que a Cristo.

São tratados de forma radicalmente diferentes os intermediários entre o sagrado e o homem que, apesar do contato com o histórico, conserva os principios arcaicos. Ainda que as pessoas do sexo masculino também possam exercer papéis sagrados, são as mulheres as detentoras de maiores poderes mágicos, lembrando as sacerdotisas e a grande deusa presentes em diversas tradições, bem como podendo ter um substrato das sociedades matriarcais. As feiticeiras nāo escolhem o "métier" nem são eleitas pela comunidade. predestinação que pode obedecer uma linhagem de sangue ou uma linhagem espiritual, e não admite recusa. Embora os brancos não as reconheçam como diferenciadas, os fiéis lhes prestam homenagem, respeitam e buscam seu auxilio 
tanto para as questōes espirituais como terrenas, uma vez que o arcaico vê o mundo como unidade.

A primeira a aparecer, tanto no plano da história como na narração é Dadinha, focalizada na comemoração de scus cem anos, dia de sua morte, como previra. A herança que deixa a seu povo é todo o seu saber condensado num discurso que narra a sua vida e a história do Brasil da ótica popular, de mistura com toda uma tradição judaico-cristã. Ela ensina sobre o comportamento da natureza e a cura com ervas. A origem de Dadinha é duplamente arcaica, sontando ainda com um ancestral civilizado. Ela é neta de Vu, a filha do caboco Capiroba que se acasalara com um holandês preso para ser comido. As reações violentas de $\mathrm{Vu}$ quando aprisionada, incapaz de adaptar-se aos costumes da vila, são vistas como obra do demônio e, como exorcismo, enterram-na viva, tratamento dispensado às bruxas para salvá-las dessa condição. Daí nasce a bananeira brava, conta Dadinha. Eliade registra diversos mitos paralelos como explicação para a origem de muitos vegetais. Questionar se Dadinha sabe tudo isso pela longa vida, pelo que se conservara na tradição oral ou pelo que os espíritos lhe comunicaram não altera seu caráter sacral. Esse saber é o mesmo que poder, e não pode ser avaliado pelo pensamento analíticoracional.

A herdeira da tradição de Dadinha é Nega Inảcia, sucedida por Sá Rufina, que a transfere a Rita Popó. Com variantes minimas no procedimento, todas exercem a mesma função, particularizando-se na economia da narrativa, como personagens secundárias.

Se todas essas feiticeiras precisam equilibrar-se nas fronteiras do universo sagrado legado pelos ancestrais e do espaço profano que as exige como força de trabalho prociutivo, a última consegue viver numa comunidade que escapa às leis do capitalismo emergente, último reduto onde o sagrado e o profano não se distinguem. Como não podia deixar de ser, essa comunidade, dificílima de ser localizada, situa-se em Amoreiras. Nas cercanias nega-se ou cala-se sobre sua existência, "uma espécie de terreiro cercado por várias construções, escondido num matagal desguedelhado, de trilhas tortuosas." (p. 594) Aí Rita Popó é uma espécie de sacerdotisa-rainha. Sua função de iniciadora, de guia, seja nos mistérios da religiāo seja nos segredos da vida, o que ai é a mesma coisa, é claramente definida.

Entre os homens, o único denominado feiticeiro é Júlio Dandão. Mas ele não participa dos cerimoniais descritos aqui. Mesmo para o leitor mostra-se uma figura misteriosa a prin- 
cipio, para se revelar um revolucionário. Sua preocupação é eminentemente social. Ele é o possivel fundador de Irmandade do Povo Brasileiro, irmandade secerta cujo ponto de partida pode ser a reunião dos conspiradores negros que matam o barāo por envenenamento com ervas. A primeira vista parece que para rastrear o jogo de velação/revelaçāo dessa irmandade é possivel obedecer o mesmo método aplicado até aqui para detectar o arcaico. Entretanto, embora seja possível comprovar que o narrador vai erigindo-a pelo modelo das sociedades secretas de caráter sagrado, o desenrolar da ação mostra que sua funçāo se redimensionará se examinada pelo seu caráter metafórico, para atingir o cerne da problemática social. Assim, a canastra, que funciona como repositório do saber, a Casa da Farinha, espaço sempre ligado à irmandade, e a mariposa curuquerê, marca de má sorte, exigem um aprofundamento no estudo do simbolo.

A construção das personagens Maria da Fé e Patricio Macário oferece uma enorme gama de elementos mágicos. O levantamento dessas características revelou serem täo re. levantes que exigem a exploração mais detalhada de um aspecto do sagrado, a construção do mito. São dois temas para a continuação deste estudo.

Esta proposta de leitura procurou evidenciar que, para recriar esteticamente o surgimento da naçäo brasileira, no seu complexo jogo de forças sociais e econômicas, onde se fundem concepçōes européis importadas, tradições africanas transplantadas e costumes autóctones desfigurados, uma das soluçōes foi sublinhar os efeitos do confronto do arcaicn con o civilizado. A obra questiona insistentemente o ideal de pr.J. gresso como sinônimo de evolução da sociedade no sentido de aperfeiçoamento. $A$ medida que o choque vai dando lugar à acomodação, com a crescente afirmação do historicismo, a sociedade vai se superficializando e desestruturando espiritualmente. Eliade fala da "nostalgia do paraiso" e do "terror da história"i, vendo na literatura uma das compensaçōes modernas pela perda da condição arcaica. Mas nós, leitores, acabamos traindo essa função, dividindo analiticamente 0 que só pode ser visto como unidade, realização absoluta e incorruptivel, ponto de encontro da arte com 0 arcaico. 


\section{REFERENCIAS BIBLIOGRAFICAS}

1 CONTI, Mário Sérgio. Um brado retumbante; no romance Viva o Povo Erasileiro, João Ubaldo recria mais de 300 anos de história. Veja, 850:109-10, 19 dez. 1984.

2 ELIADE, Mircea. Le chamanisme et les techniques archaiques de l'extase. Paris, Payot, 1951. 407 p.

3 - O mito do eterno retorno. Lisboa, Ed. 70, 1981. 175 p.

4 - Mito e realidade. São Paulo, Perspectiva, 1972. 183 p.

5 - O sagrado e o profano; a essência das religiōes. Lisboa, Llvros do Brasil, s. d. 235 p.

6 - Traité dhistoire des religions. Paris, Payot, 1953. 405 p.

7 RIBEIRO, João Ubaldo. Viva o povo brasileiro. Rio de Janeiro, Nova Fronteira, 1984. $673 \mathrm{p}$.

B SERRA, Cristina. A formação da nacionalidade brasileira como foi vista por João Ubaldo Ribelro, na mansidão da ilha de Itaparíca. Leia, Sāo Paulo, y(75):10-1, jan. 1985. 